\title{
Albumin-bilirubin score: an additional tool for the management of patients with hepatocellular carcinoma
}

\author{
Matteo Serenari, Giorgio Ercolani \\ Department of Medical and Surgical Sciences, University of Bologna, Bologna, Italy \\ Correspondence to: Giorgio Ercolani. Department of Medical and Surgical Science, University of Bologna, Bologna, Italy; Director of Department of \\ Surgery, City Hospital in Forlì, Forlì, Italy. Email: giorgio.ercolani2@unibo.it. \\ Comment on: Feng D, Wang M, Hu J, et al. Prognostic value of the albumin-bilirubin grade in patients with hepatocellular carcinoma and other liver \\ diseases. Ann Transl Med 2020;8:553.
}

Submitted Jul 02, 2020. Accepted for publication Jul 20, 2020.

doi: 10.21037/atm-20-5086

View this article at: http://dx.doi.org/10.21037/atm-20-5086

We read with great interest the article written by Feng and colleagues published in the issue of April in Annals of Translational Medicine (1). The authors reviewed all the studies that examined the prognostic value of albuminbilirubin (ALBI) score in patients mostly affected by hepatocellular carcinoma (HCC).

ALBI grade was first proposed by Johnson et al. in 2014 (2) to offer a more objective method to assess liver function in HCC patients, thus eliminating subjective variables such as ascites and encephalopathy which are required in traditional Child-Pugh $(\mathrm{CP})$ classification. Both European Association for the Study of the Liver (EASL) and American Association for the Study of Liver Diseases (AASLD) guidelines for the treatment of HCC endorse the Barcelona Clinic Liver Cancer (BCLC) classification. BCLC staging system consists of five stages and allocates patients according to pre-established prognostic variables. Among them, a preserved liver function defined as CP class A without any ascites is a prerequisite which applies to all treatment options except for liver transplantation. However, ALBI grade seemed to improve the accuracy of prognosis, and ALBI grade 1 patients, as showed in Table 1 of the manuscript, had a significantly better survival compared to those classified as ALBI grade 2/3, even within the same CP class (3). This would mean that such a variation in the prognosis, related to a more precise assessment of the underlying liver function, may potentially change the type of intervention to which a patient could be candidate.

Therefore, ALBI grade represents an additional tool to help clinicians in determining the best treatment option for HCC patients (4). First, among optimal surgical candidates (BCLC 0-A) ALBI score has been demonstrated to better predict the risk of decompensation after hepatectomy (ALBI grade $2 / 3$ ), including also minimally-invasive liver resections (5), compared to traditional indices (6). Hence, a high-risk subgroup of patients may be identified and benefit more from less invasive treatments such as radiofrequency ablation (RFA) or even to liver transplantation, when survival advantage obtained with liver resection is limited (7). Despite clear advantages and better prognostic value of ALBI grade compared to CP score, some authors considered such a difference not clinically relevant. On the other hand, it should be emphasized that other tests and scores have been validated in the evaluation of patients with HCC waiting for liver resection. MELD score better stratifies cirrhotic patients with HCC for partial hepatectomy than CP classification $(8,9)$. Many Eastern and Western surgeons commonly apply indocyanine green test to select patients for liver resection (10).

Besides BCLC 0-A, patients classified as BCLC B represent an even more heterogeneous population. Although transarterial chemoembolization (TACE) is recommended for these patients, other treatments such as radioembolization, RFA or even surgical resection, have been explored in the past and might be suited to BCLC B patients based on ALBI classification $(11,12)$. On the other side, ALBI-based BCLC may upstage a significant number of patients from CP class B to ALBI grade 3 (or ALBI-based BCLC stage D) (12) (i.e. with an observed survival $<3$ months), thus optimizing also administration of 
experimental therapies in advanced HCC (13).

Though Feng and co-workers report the usefulness and superiority of ALBI grade even in other liver disease, we should remember that at the moment incorporation of hyponatremia into MELD score (MELD-NA) showed the best prognostic factor in patients waiting for liver transplantation (14). Similarly incorporating ICG into MELD (MELD-ICG) score seems to better discriminate intermediate to advanced cirrhotic patients (15).

Anyway, we would like also to highlight the potential role of ALBI score in predicting HCC recurrence. Although the Authors in their review article did not cover this topic, ALBI grade together with other risk factors, has been demonstrated to predict early and de novo recurrence after hepatectomy, thus contributing in guiding surveillance follow-up and in the design of clinical trials $(16,17)$.

In conclusion, ALBI grade seems to be a reliable marker of hepatic function, both in HCC and other liver disease. It is much more effective than CP in stratifying patients waiting for liver resection or other treatment and it seems to work as a prognostic factor for recurrence. However, prospective studies comparing ALBI grade to MELD-NA or MELD-ICG in HCC and cirrhotic patients are required to define which might perform better.

\section{Acknowledgments}

Funding: None.

\section{Footnote}

Provenance and Peer Review: This article was commissioned by the editorial office, Annals of Translational Medicine. The article did not undergo external peer review.

Conflicts of Interest: Both authors have completed the ICMJE uniform disclosure form (available at http://dx.doi. org/10.21037/atm-20-5086). Both authors have no conflicts of interests to declare.

Ethical Statement: The authors are accountable for all aspects of the work in ensuring that questions related to the accuracy or integrity of any part of the work are appropriately investigated and resolved.

Open Access Statement: This is an Open Access article distributed in accordance with the Creative Commons Attribution-NonCommercial-NoDerivs 4.0 International
License (CC BY-NC-ND 4.0), which permits the noncommercial replication and distribution of the article with the strict proviso that no changes or edits are made and the original work is properly cited (including links to both the formal publication through the relevant DOI and the license). See: https://creativecommons.org/licenses/by-nc-nd/4.0/.

\section{References}

1. Feng D, Wang M, Hu J, et al. Prognostic value of the albumin-bilirubin grade in patients with hepatocellular carcinoma and other liver diseases. Ann Transl Med 2020;8:553.

2. Johnson PJ, Berhane S, Kagebayashi C, et al. Assessment of Liver Function in Patients With Hepatocellular Carcinoma: A New Evidence-Based Approach-The ALBI Grade. J Clin Oncol 2015;33:550-8.

3. Toyoda H, Lai PBS, O'Beirne J, et al. Long-term impact of liver function on curative therapy for hepatocellular carcinoma: Application of the ALBI grade. Br J Cancer 2016;114:744-50.

4. Pasini F, Serenari M, Cucchetti A, et al. Treatment options for recurrence of hepatocellular carcinoma after surgical resection: review of the literature and current recommendations for management. Hepatoma Res 2020;6:26.

5. Sposito C, Monteleone M, Aldrighetti L, et al. Preoperative predictors of liver decompensation after mini-invasive liver resection. Surg Endosc 2020. [Epub ahead of print].

6. Fagenson AM, Gleeson EM, Pitt HA, et al. AlbuminBilirubin Score vs Model for End-Stage Liver Disease in Predicting Post-Hepatectomy Outcomes. J Am Coll Surg 2020;230:637-45.

7. Chong CCN, Chan AWH, Wong J, et al. Albuminbilirubin grade predicts the outcomes of liver resection versus radiofrequency ablation for very early/early stage of hepatocellular carcinoma. Surgeon 2018;16:163-70.

8. Cucchetti A, Ercolani G, Vivarelli M, et al. Impact of model for end-stage liver disease (MELD) score on prognosis after hepatectomy for hepatocellular carcinoma on cirrhosis. Liver Transpl 2006;12:966-71.

9. Delis SG, Bakoylannis A, Billatis I, et al. Model for endstage liver disease (MELD) score, as a prognostic factor for postoperative morbidity and mortality in cirrhotic patients, undergoing hepatectomy for hepatocellular carcinoma. HPB 2009;11:351-7.

10. Mise Y, Hasegawa K, Satou S, et al. Venous reconstruction 
on virtual liver resection to avoid congestion in the liver remnant. Br J Surg 2011;98:1742-51.

11. Pinato DJ, Sharma R, Allara E, et al. The ALBI grade provides objective hepatic reserve estimation across each BCLC stage of hepatocellular carcinoma. J Hepatol 2017;66:338-46.

12. Chan AWH, Kumada T, Toyoda H, et al. Integration of albumin-bilirubin (ALBI) score into Barcelona Clinic Liver Cancer (BCLC) system for hepatocellular carcinoma. J Gastroenterol Hepatol 2016;31:1300-6.

13. Ueshima K, Nishida N, Hagiwara S, et al. Impact of baseline ALBI grade on the outcomes of hepatocellular carcinoma patients treated with lenvatinib: A multicenter study. Cancers (Basel) 2019;11:952.

14. Kim WR, Biggins SW, Kremers W, et al. Hyponatremia

Cite this article as: Serenari M, Ercolani G. Albumin-bilirubin score: an additional tool for the management of patients with hepatocellular carcinoma. Ann Transl Med 2020;8(19):1207. doi: 10.21037/atm-20-5086 and mortality among patients on the liver transplant waiting list. N Engl J Med 2008;359:1018-26.

15. Zipprich A, Kuss O, Rogowski S, et al. Incorporating indocyanine green clearance into model for end stage liver disease improves prognostic accuracy in intermediate to advanced cirrhosis. Gut 2010;59:963-8.

16. Chan AWH, Zhong J, Berhane S, et al. Development of pre and post-operative models to predict early recurrence of hepatocellular carcinoma after surgical resection. J Hepatol 2018;69:1284-93.

17. Hsu HY, Yu MC, Lee CW, et al. RAM score is an effective predictor for early mortality and recurrence after hepatectomy for hepatocellular carcinoma. BMC Cancer 2017;17:742. 